\title{
Temporal and spatial variations in lice numbers on salmon farms in the Hardanger fjord 2004-06
}

\author{
P A Heuch ${ }^{1}$, R S Olsen ${ }^{2}$, R Malkenes ${ }^{2}$, C W Revie ${ }^{3}$, G Gettinby ${ }^{3}$, M Baillie ${ }^{3}$, F Lees $^{3}$ and \\ B Finstad ${ }^{4}$
}

1 National Veterinary Institute, Oslo, Norway

2 Hardanger Fish Health Network, Tysnes, Norway

3 Epi Informatics, University of Strathclyde, Glasgow, UK

4 Norwegian Institute for Nature Research, Trondheim, Norway

\begin{abstract}
The long and narrow Hardanger fjord in western Norway has a high density of salmon farms and has had severe salmon lice, Lepeophtheirus salmonis, problems. In the years 2004 06, salmon lice numbers were recorded in selected salmon farms in the fjord as part of a larger research project. Most farm sites participated in a strategic control pro gramme and were deloused between November and January in each year. The aim of the programme was to achieve a mean abundance of $<0.3$ adult female lice at this time and to minimize the infec tion pressure on wild smolts in the spring. Dedi cated teams carried out detailed counting of lice on farmed fish in April September each year. Tem perature conditions were fairly similar throughout the fjord and amongst years, but wide variations in salinities were observed. The two innermost zones, $\mathrm{B}$ and $\mathrm{C}$, had the lowest lice mean abundances, whereas the outermost zones, D and E, consistently had more lice. General linear model analyses showed that differences in adult female lice abun dance between the zones were associated with dif fering levels of salinity and emamectin benzoate treatments strategically administered. Mean fish weight was significantly positively correlated with mean abundance of adult female lice.
\end{abstract}

Keywords: abundance, epidemiology, Lepeophtheirus salmonis, Norway.

Correspondence $P$ A Heuch, National Veterinary Institute, $P O B$ 750 Sentrum, 0106 Oslo, Norway

(e mail: peter andreas.heuch@vetinst.no)

\section{Introduction}

The salmon louse, Lepeophtheirus salmonis (Krøyer, 1837), is one of the most costly pests in the salmon farming industry in the Northern Hemisphere (Johnson, Treasurer, Bravo, Nagasawa \& Kabata 2004). Salmon farmers need to keep lice abun dances low not only to avoid damage on the farmed fish, but also to minimize the number of planktonic parasite stages released into the water. These stages readily disperse through the open net pens and may later infect farmed or wild salmonids in the surrounding areas.

In Norway, the salmon farming industry is the dominant source of salmon lice because of the high number of fish in farms (Heuch \& Mo 2001; Heuch, Bjørn, Finstad, Holst, Asplin \& Nilsen 2005). The population of lice on Atlantic salmon, Salmo salar L., and rainbow trout, Oncorhynchus mykiss (Walbaum), in farms on the Norwegian coast from the county of Vest Agder to the county of Troms was estimated to produce $c a 100$ times as many lice eggs as the lice on wild sea going Atlantic salmon, sea trout, Salmo trutta L. and sea charr, Salvelinus alpinus L., in the spring of 2000 (Heuch $\&$ Mo 2001). Whereas the number of wild hosts in spring has most likely remained at ca 750000 (Heuch \& Mo 2001) or has declined, the number of farmed fish hosts in this area is now higher (estimated to be 236000000 in December 2006, Norwegian Fisheries Directorate 2008). The Nor wegian authorities enforce a limit of 0.5 adult female lice per fish, above which the site should be treated with a delousing medicine or cleaner fish 
within 14 days (Heuch et al. 2005). The stated goal of this regulation is to "minimize infections of wild and farmed salmonids' (Heuch et al. 2005). How ever, heavily infected sea trout and sea charr have been found in several salmon farming areas (Heuch et al. 2005; Bjørn, Finstad, Nilsen, Skaala \& Øverland 2007; Kålås \& Urdal 2007, and refer ences therein).

In some areas local lice limits have been agreed by fish health networks. One of these is the Hardanger Fish Health Network (HFN), which operates in the Hardanger fjord on the south west coast of Norway. Members of this network aim to keep a mean abundance of $<0.25$ adult females from 1 December to 1 July. Since 2004, the HFN has been coordinating strategic delousing pro grammes in winter. The aim of these programmes has been to achieve a mean abundance of $<0.3$ lice in total at this time, to minimize the infection pressure on wild smolts and newly stocked farm fish in spring. Farmer counts indicate a very low abundance of adult female lice in the target period, week 20 (Olsen 2005, 2007).

The strategic delousing efforts form part of a research project, which aims to document the relationship between all salmon lice infection sources and hosts in the fjord. The project inves tigates salmon lice abundance on wild and escaped Atlantic salmon and sea trout, compares monitoring and control procedures in salmon farms, monitors dispersal of salmon lice larvae and relates these to oceanography and salmon migration routes. For the lice monitoring part, dedicated teams carry out detailed counting of lice on fish from a sample of farm sites from April to September in each year. This communication describes the development of the lice populations on these sites in 200406 .

Salmon lice are euryhaline, but fresh water will strongly influence survival of both parasitic and free swimming stages (Johnson \& Albright 1991a). Parasitic lice include four chalimus stages anchored in the fish skin, two motile preadult stages and the motile adult stage (Johnson \& Albright 1991b). The free swimming stages, including the two nauplius stages and the infective copepodid, migrate vertically to find a salinity in which they can survive (Heuch 1995). This may, however, remove them from their potential hosts. The different hydrog raphical conditions in different areas of the $165 \mathrm{~km}$ long Hardanger fjord are therefore likely to directly influence lice population dynamics. In the present study, salinity and temperature were recorded in the different zones of the fjord and their associations with salmon lice abundances were evaluated.

In Scotland, a 2 year salmon production cycle is the norm, and it has been observed that the larger, second year fish carry more lice than the first year fish (Revie, Gettinby, Treasurer, Grant \& Reid 2002b; Revie, Gettinby, Treasurer, Rae \& Clark 2002a; Lees, Gettinby \& Revie 2008). No coordinated production cycle is generally practised in the Hardanger fjord, but to investi gate a possible accumulation of lice as the fish grow, mean fish weight was included as a variable in the analyses of factors which may influence parasite abundance.

\section{Materials and methods}

\section{Area and farming activity}

The Hardanger fjord was divided into five zones, designated $\mathrm{A}$ through $\mathrm{E}$, where $\mathrm{A}$ is the innermost zone (Fig. 1). The number of stocked farm sites, along with the number that were monitored for lice by the dedicated count team, in each zone in each year is given in Table 1 . There was no fish farming activity in zone $\mathrm{A}$. The area encompassing the other four zones is $125 \mathrm{~km}$ long and between 2 and $7 \mathrm{~km}$ wide. Eleven salmon rivers, in addition to numer ous smaller rivers, flow into the fjord (Otterå, Skilbrei, Skaala, Boxaspen, Aure, Taranger, Ervik \& Borgstrøm 2004).

Sixteen of the 18 salmon farming companies in the fjord are members of the HFN, accounting for approximately $95 \%$ of the total salmon biomass in the fjord. The two non members have three to four active sites in the northern part of zone D. The outermost two zones are close to other salmon farming areas south and north of the mouth of the fjord. Data from these areas were not collected. The HFN collects sea lice data from $c a 40$ sites (Table 1) where Atlantic salmon are stocked in open net cages. In 2004 06, ca 12 million smolts were stocked annually on these sites.

The HFN recommended that sites where the total number of adult female lice per fish was above 0.3 should delouse. Fish in their second year at sea were generally treated topically with pyrethroids, whereas first year fish were given in feed emamectin benzoate $\left(\right.$ SLICE $^{\circledR}$ ) if the site abundance was above the limit. In this study delousing which took place between week 48 of 1 year and week 4 of the next was considered a strategic treatment. 


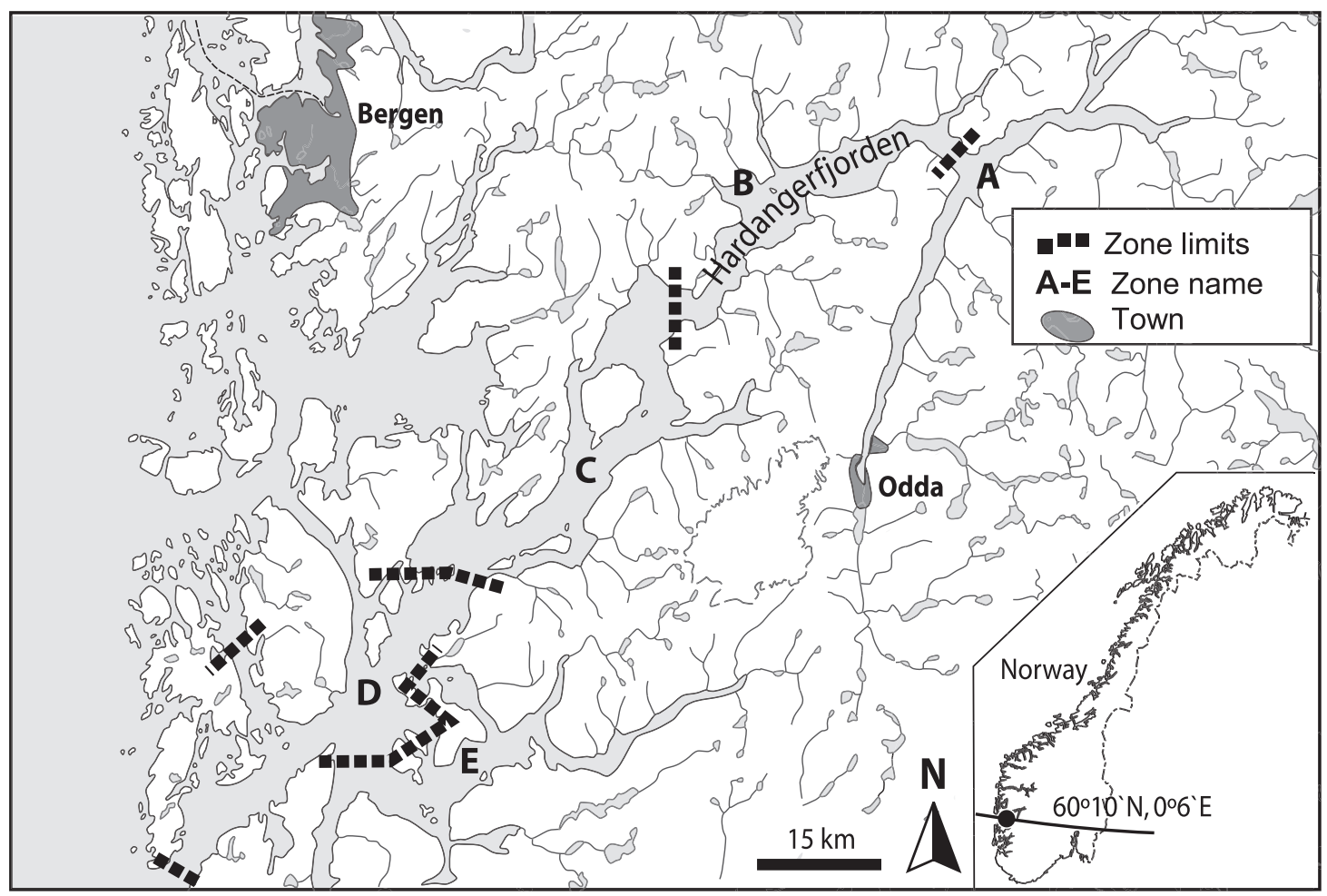

Figure 1 Map of the Hardanger fjord in south-western Norway. Fjord zones are delineated by dotted lines and designated A-E.

Table 1 The number of Hardanger Fish Health Network (HFN) sites, and the number of these which were sampled in the project. The number of sites stocked during or after the strategic treatment is given in parentheses

\begin{tabular}{|c|c|c|c|c|}
\hline \multirow[b]{2}{*}{ Zone } & \multirow[b]{2}{*}{ Number of sites in zone in spring } & \multicolumn{3}{|l|}{ Year } \\
\hline & & 2004 & 2005 & 2006 \\
\hline \multirow[t]{4}{*}{ B } & HFN total sites & 8 & 7 & 9 \\
\hline & Strategically deloused HFN sites & $0^{*}$ & 6 & 6 \\
\hline & Sites counted by teams & 6 & $5(2)$ & $5(1)$ \\
\hline & Strategically deloused counting sites & $0^{*}$ & 2 & 3 \\
\hline \multirow[t]{4}{*}{ C } & HFN total sites & 17 & 18 & 17 \\
\hline & Strategically deloused HFN sites & $0^{*}$ & 9 & 12 \\
\hline & Sites counted by teams & 8 & $9(2)$ & $8(2)$ \\
\hline & Strategically deloused counting sites & $0^{*}$ & 4 & 6 \\
\hline \multirow[t]{4}{*}{ D } & HFN total sites & 7 & 5 & 5 \\
\hline & Strategically deloused HFN sites & $0^{*}$ & 3 & 4 \\
\hline & Sites counted by teams & 5 & $4(1)$ & $5(2)$ \\
\hline & Strategically deloused counting sites & $0^{*}$ & 2 & 4 \\
\hline \multirow[t]{4}{*}{ E } & HFN total sites & 7 & 10 & 7 \\
\hline & Strategically deloused HFN sites & $0^{*}$ & 3 & 6 \\
\hline & Sites counted by teams & 2 & $4(1)$ & $4(1)$ \\
\hline & Strategically deloused counting sites & $0^{*}$ & 1 & 3 \\
\hline
\end{tabular}

*There was no coordinated delousing in 2003/2004.

\section{Lice counting}

Bi weekly salmon louse counts were performed by dedicated teams of trained personnel in weeks 20 34 in 2004, weeks 1638 in 2005 and weeks 1638 in 2006. These time periods were chosen to evaluate the salmon louse infection pressure from farm sites during the wild smolt run, which usually occurs in weeks 1820 (Ø. Skaala, Institute of Marine Research, Bergen, personal commmunication). Approximately 20 sites were selected for monitoring each year on the basis of geographical distribution, 
distribution between companies and fish year classes (Table 1). Occasionally lice counting could not be carried out on a site because of various husbandry operations or viral disease on the site. On each site, at each sample point, at least 40 fish were caught by seine or dip net from a minimum of two pens. The fish were anaesthetized, and $L$. salmonis of the groups 'chalimus', 'preadults', 'adult males' and 'adult females' were enumerated and recorded for each fish. Data are presented as the mean abun dance (Bush, Lafferty, Lotz \& Shostak 1997) of a particular stage in each zone, i.e. the mean number of lice per fish based on the available sample in the respective weeks.

Information on stocking and salmon lice treat ments was accessed through the HFN or directly at each site. Weekly averages of temperature and salinity at $3 \mathrm{~m}$ depth from sites where this infor mation was available were collected by the HFN. Temperature was recorded by a sensor at $c a 3 \mathrm{~m}$ depth on most farms. Salinity at $3 \mathrm{~m}$ depth was recorded on some farms in each zone. Additional salinity data were obtained from CTD casts per formed during Institute of Marine Research cruises.

\section{Data management and statistical analysis}

Data were stored and managed using a set of structured tables in Microsoft Access 2003. This application was also used to calculate mean sea lice abundance values. All figures were constructed using Microsoft Excel 2003 while statistical analyses were performed within Minitab 15.1. Bi weekly mean abundance values for the chalimus and adult female stages, in each zone and in each year, were calculated by pooling all available lice counts per fish.

A statistical model to determine the factors associated with adult female L. salmonis lice abun dance was investigated using a General Linear Model (GLM) procedure. Prior to GLM analysis, lice count and fish weight data were summarized by calculating the mean in each sampled pen at each sample point on each farm. To improve normality and equalize variances, lice count data were square root transformed $[\operatorname{sqrt}(\mathrm{x})]$. Significant findings are reported at the $5 \%$ level. To aid interpretation of the final models, least squares means were subse quently untransformed and reported.

As salinity readings were not available for all sites from which lice data were collected in each year, zone level averages were used in the GLM analysis.
Weekly salinity values were calculated by pooling all available site salinity readings in each zone in each week; these weekly values were then pooled to calculate a mean salinity value for the lice count period in each zone in each year. These salinity values were ranked and divided into three equal parts allowing each zone/year salinity value to be classified as low $(<22.7 \% \mathrm{~S})$, medium (22.7 $26.8 \%$ S) or high $(>26.8 \% \mathrm{~S})$.

For the GLM analysis, delousing treatments were divided into two categories. Those that took place on a site between week 48 of the previous year and week 15 of the current year were classified as pretreatments the majority of which were strategic treatments that occurred before week 4; treatments that took place after week 15 , but before the date of each lice count, were classified as peri treatments. For each of these treatment periods it was noted whether a site had received no treatments, had applied a pyrethroid, had used emamectin benzoate or had administered both types of delousing medicine. Treatments that were given after the lice count period, but before week 48 of the current year, were not included in the analysis. For each lice count, at each site, the factor 'Pretreatment type' thus took the values None, Pyrethroid, or Ema mectin benzoate. The factor 'Peri treatment type' could in addition be Both.

\section{Results}

\section{Salmon louse population dynamics}

The proportion of sites participating in the strategic delousing programme varied between zones and years (Fig. 2, Table 1). The programme started in December 2004, so the spring counts of that year do not reflect a coordinated louse treatment effort. Effects of the 200405 programme can be seen in the figures from weeks 16 to 36 in 2005, and the 200506 programme in weeks 16 to 38 in 2006 (Fig. 2).

Sites in zone B, the innermost zone, had the lowest lice abundances, and stayed below the local limit of $<0.25$ adult female lice in week 20 in all years (Fig. 2a). In 200405 and 200506 all but one of the sampled sites in the zone had deloused strategically (Table 1) and there were no further treatments at the sampled sites until week 24 (2006). Zone C lice mean abundances followed a similar pattern, but sites were treated more frequently around week 20 in 2004 and in the 


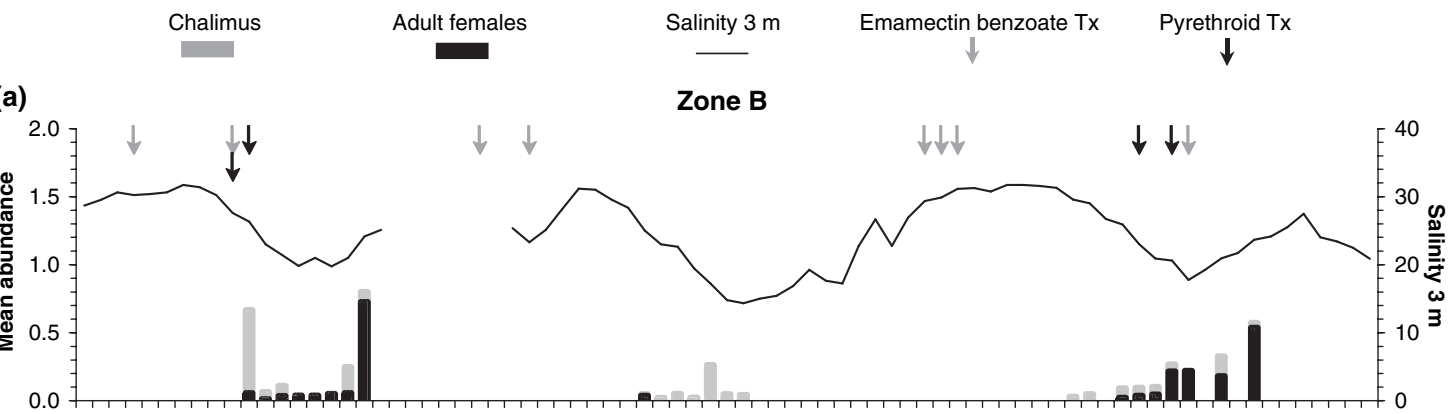

$524 \quad 8 \quad 12162024283236404448524 \quad 8 \quad 121620242832364044485244 \quad 8 \quad 1216202428323640444852$ 2004 $($ Sites = 6)

2005

$($ Sites $=5)$

Year / Week
2006

$($ Sites $=5)$

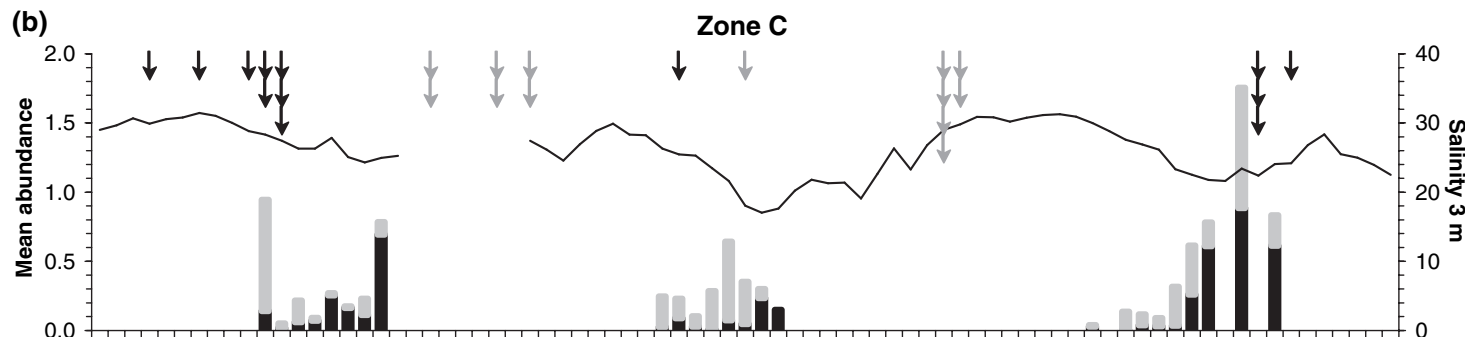

$524 \quad 8 \quad 1216202428323640444852 \quad 4 \quad 8 \quad 12162024283236404448524 \quad 8 \quad 1216202428323640444852$ 2004

$($ Sites $=8)$

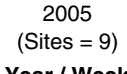

Year / Week

(c)

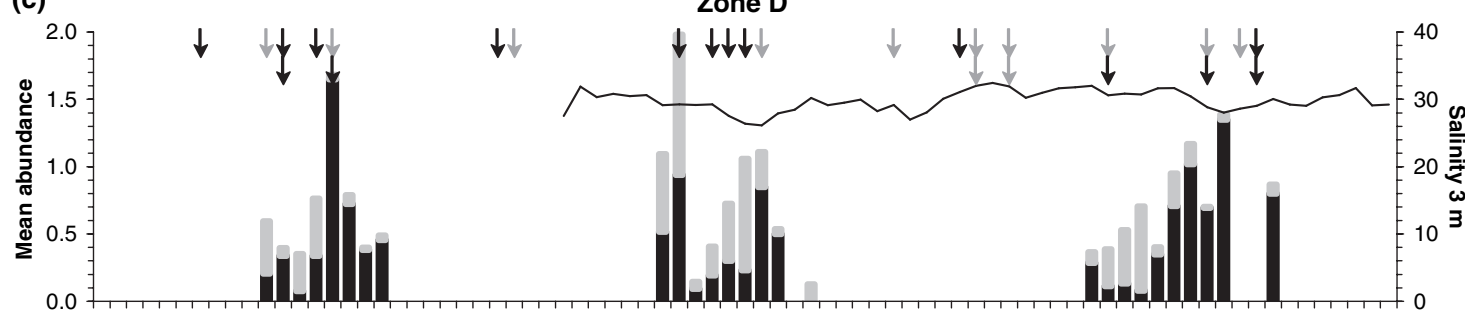

$524 \quad 8 \quad 12162024283236404448524 \quad 8 \quad 121620242832364044485244 \quad 8 \quad 1216202428323640444852$

2004

$($ Sites $=5)$
2005

$($ Sites $=4)$

Year / Week
2006

$($ Sites $=5)$

(d)

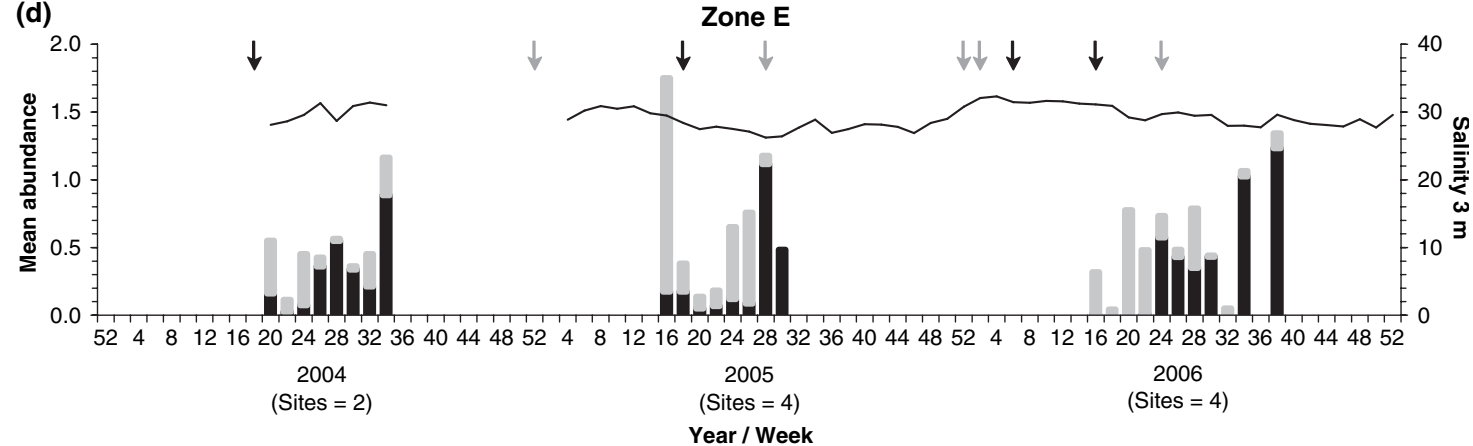

Figure 2 Mean bi-weekly Lepeophtheirus salmonis chalimus and adult female abundance in the Hardanger fjord, by zone, between 2004 and 2006. 
autumn of that year. The strategic treatments in 200405 excluded three sites (Table 1), but the adult female louse mean abundances in weeks 16 20 of 2005 were very low. Similar results were recorded in the target period after strategic treat ments of 2005 06, which included all relevant sites (Fig. 2b). In both zones B and C, adult female lice mean abundances were extremely low in weeks 16 20 in 2006, and the rates of development of chalimus into adult from week 24 to 34 were much higher in this year than in 2005.

Zones D and E, the outermost zones, showed a different pattern of infection. Through the counting period in 2004 lice abundances were distinctly higher, breaking the 0.25 adult female lice limit at most sample points. In zone $\mathrm{D}$, the national limit of 0.5 adult female lice was also exceeded in weeks 28 and 30 (Fig. 2c). In zone D, six treatment events were recorded in this period, and a mean adult female abundance below 0.5 followed in weeks 32 and 34 . In zone E, only one site was deloused before week 20 , and the mean adult female abundance in week 34, 2004 exceeded the national limits.

Few sites in zones $\mathrm{D}$ and $\mathrm{E}$ participated in the strategic delousing programme of 2004 05, but only one (in D) and two (in E) of the sampling sites chose not to delouse at the time (Table 1, Fig. 2c, d). The local limit was exceeded in most weeks in 2005, but the louse population structure was quite different in the two zones. In zone $\mathrm{D}$, the mean abundance of adult female lice was at or above 0.5 lice in week 16 and 18, as were the number of chalimus observed on the fish. In zone $\mathrm{E}$, the abundance of adult females was only 0.2 in the same weeks, but the fish carried a mean of 1.6 chalimus in week 16. Treatments reduced the lice abundances somewhat, but new infections were recorded in 24 and 26, and subsequently high adult female abundances in weeks 28 and 30 in both zones were observed (Fig. 2c, d). In 2005 06, most sites participated in the strategic delousings. Cha limus dominated the recorded louse populations in weeks 1622 in zones D and E, but from week 24, the lice were predominantly adults. Although several treatments were administered, the mean abundance of adult females exceeded 0.5 in five out of seven weeks in zone D, and two out of seven in zone $\mathrm{E}$ in weeks 2638 .

The average time between the last strategic treatment against lice and the next treatment in the zones was 26 weeks in 2005 and 20 weeks in 2006 (Table 2). However, farms in zones B and C
Table 2 Time in weeks between last strategic treatment and first subsequent treatment against salmon lice, Lepeophtheirus salmonis, on farmed Atlantic salmon, Salmo salar, in the different zones of the Hardanger fjord, Norway

\begin{tabular}{|c|c|c|c|}
\hline Zone & 200405 & 200506 & Mean across years \\
\hline B & 48 & 22 & 35 \\
\hline C & 18 & 34 & 26 \\
\hline $\mathrm{D}$ & 20 & 12 & 16 \\
\hline$E$ & 18 & 10 & 14 \\
\hline Mean across zones & 26 & 20 & \\
\hline
\end{tabular}

could wait much longer before treating than farms in zones $\mathrm{D}$ and $\mathrm{E}$.

\section{Temperatures}

The mean temperatures in the different zones appear strikingly similar throughout the study period, rarely differing by more than $1{ }^{\circ} \mathrm{C}$ (Fig. 3). However, the summer temperatures of 2006 were higher than the other years, and the spring warming in this year came earlier in zones $\mathrm{B}$ and $\mathrm{C}$ than in $\mathrm{D}$ and $\mathrm{E}$.

\section{Salinity}

The zones and years were different with respect to water salinity (Fig. 2). Zones B and C showed seasonal variation where salinity in autumn and winter reached $31 \%$ S, but fell to below $20 \%$ s in spring. In both zones, the longest period in which the water was $<20 \% \mathrm{~S}$ occurred in 2005 . Zone B salinity stayed below $20 \% \mathrm{~S}$ in weeks 2242 , and zone $C$ salinity was lower than $20 \% \mathrm{~S}$ in weeks 2630 in this year. In zones D and E, the salinity was around $29 \% \mathrm{~S}$ the whole year.

\section{General linear model analyses}

A series of nested factorial models were developed to identify important factors associated with adult female louse abundance. The first model examined the role of the factors zone and year and took the form:

$$
\begin{aligned}
y= & \mu+\text { mean fish weight }+ \text { zone }+ \text { site }(\text { zone }) \\
& + \text { year }+ \text { zone } \mathrm{x} \text { year }+\epsilon
\end{aligned}
$$

where $y$ represented the square root of observed abundance at pens within each site, $\mu$ the overall mean abundance and $\epsilon$ the random error. Sites were regarded as the experimental unit and were nested 


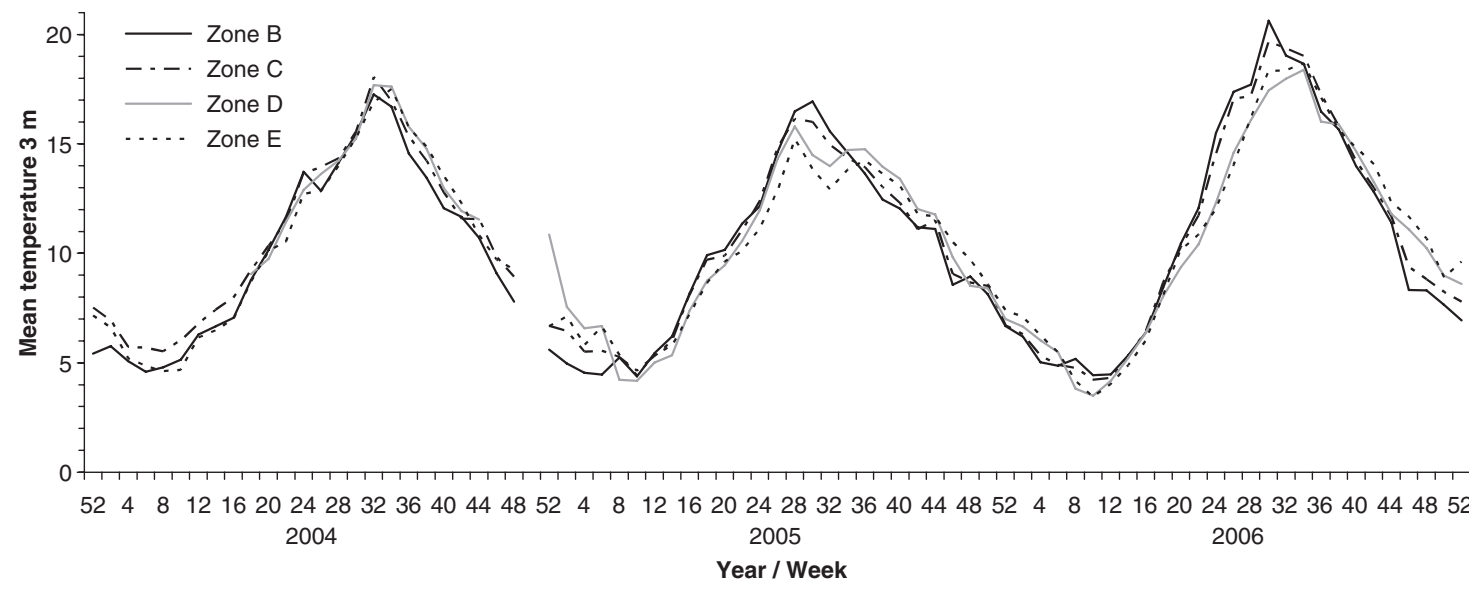

Figure 3 Mean bi-weekly sea water temperature taken at 3 metres in the Hardanger fjord, by zone between 2004 and 2006.

Table 3 Results from general linear modelling of sqrt (adult female Lepeophtheirus salmonis) lice counts, illustrating factors fitted in each model and their associated level of statistical significance

\begin{tabular}{|c|c|c|c|}
\hline Factor & Type & Levels & $P$ value \\
\hline \multicolumn{4}{|c|}{ Zone and year (model 1$), R^{2}=40.00 \%$} \\
\hline Mean fish weight ${ }^{a}$ & Continuous co variate & & 0.000 \\
\hline Site (zone) & Random & Sites 143 & 0.000 \\
\hline Zone & Fixed & $B E$ & 0.007 \\
\hline Year & Fixed & 200406 & 0.015 \\
\hline Zone $\times$ year & Fixed & & 0.000 \\
\hline \multicolumn{4}{|c|}{ Salinity level and year (model 2), $R^{2}=39.80 \%$} \\
\hline Mean fish weight ${ }^{b}$ & Continuous co variate & & 0.000 \\
\hline Site (salinity level) & Random & Sites 151 & 0.000 \\
\hline Salinity level ${ }^{*}$ & Fixed & Low, medium, high & 0.000 \\
\hline Year & Fixed & 200406 & 0.020 \\
\hline \multicolumn{4}{|c|}{ Salinity level and treatment type (model 3), $R^{2}=41.75 \%$} \\
\hline Mean fish weight ${ }^{\mathrm{C}}$ & Continuous co variate & & 0.000 \\
\hline Site (salinity level) & Random & Sites 151 & 0.000 \\
\hline Salinity level ${ }^{*}$ & Fixed & Low, medium, high & 0.024 \\
\hline Pretreatment type & Fixed & None, pyrethroid, emamectin benzoate & 0.001 \\
\hline Peri treatment type & Fixed & None, pyrethroid, emamectin benzoate, both & 0.011 \\
\hline
\end{tabular}

${ }^{a}$ Slope \pm SE $\quad 0.000186 \pm 0.000011 .{ }^{b}$ Slope \pm SE $\quad 0.000193 \pm 0.000012 .{ }^{c}$ Slope \pm SE $\quad 0.000157 \pm 0.000015 . *$ *There were no medium salinity sites in 2005 and no low salinity sites in 2006 .

within zones. In addition to zone and year, the average weight of fish in a pen was included as a continuous co variate. Further details of the terms included in the model are listed in Table 3 (model 1), where mean fish weight, zone and year were found to be significantly associated with adult female abundance. Mean fish weight was positively correlated significantly with mean abundance reflecting high lice abundances on large fish. There was a significant interaction between zone and year (Fig. 4). Zones $\mathrm{D}$ and $\mathrm{E}$ were found to have similarly shaped abundance profiles over the 3 years studied, which contrasted with the profiles for zones $\mathrm{B}$ and $\mathrm{C}$.
Consideration was given to including the effect of water temperature in the GLM analyses; how ever, exploratory analysis indicated no significant relationship to adult female lice abundance.

In the second model (Table 3, model 2), the effect of salinity was included. As salinity levels were associated with zone this led to a main effects model where the zone factor was replaced with the salinity level factor. No interaction between salin ity level (low, medium, high) and year could be included as there were no medium salinity sites in 2005 and no low salinity sites in 2006. The model, with site nested within salinity level, took the form: 


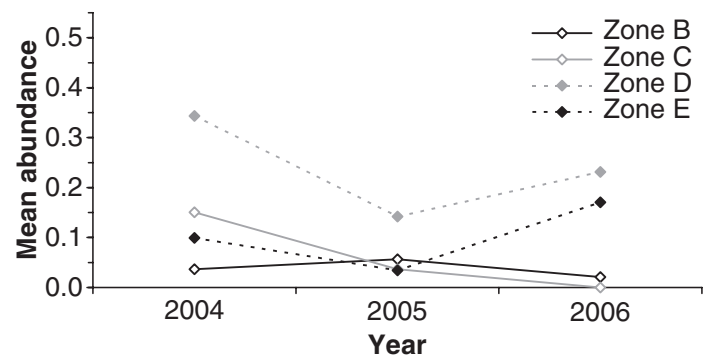

Figure 4 Profile plot of least squares mean (GLM 1) adult female Lepeophtheirus salmonis abundance, showing significant interaction between year and zone.

$$
\begin{aligned}
y= & \mu+\text { mean fish weight }+ \text { salinity level } \\
& + \text { site(salinity level })+ \text { year }+\epsilon
\end{aligned}
$$

As shown in Fig. 5a, adult female abundance was significantly lower on sites with a low or medium salinity level than on sites with a high salinity level. Lice abundance was higher in 2004 than in 2005, but no other significant differences amongst years were observed (Fig. 5b). Mean fish weight was also found to be significant in this model.

When each of the 3 years was analysed separately using both the above models, zone was not found to be significantly associated with adult female abun

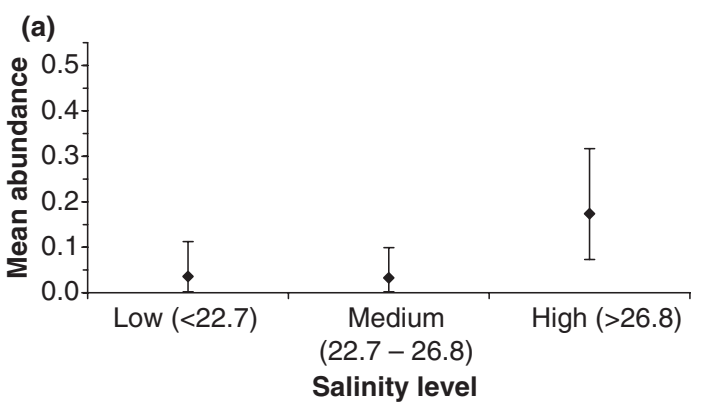

(b)

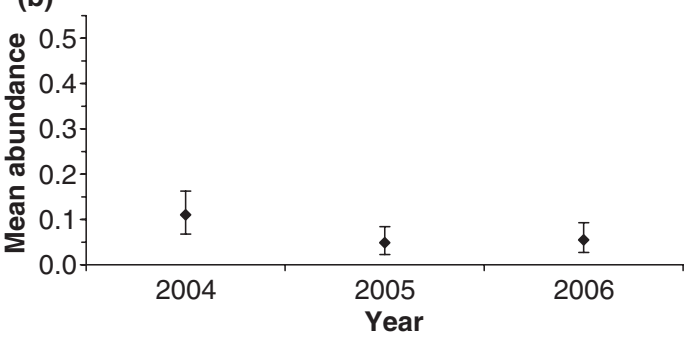

Figure 5 Profile plot of least squares mean (GLM 2) adult female Lepeophtheirus salmonis abundance $( \pm \mathrm{SE})$ by (a) salinity level; (b) year. dance, however salinity level was. This finding confirmed the significance of salinity and was the basis for not including the factor zone in the final model. The final model (Table 3, model 3) included delousing treatments in terms of when they were applied and which medicines were administered. The model took the form:

$$
\begin{aligned}
y= & \mu+\text { mean fish weight }+ \text { salinity level } \\
& + \text { site }(\text { salinity level })+\text { pretreatment type } \\
& + \text { peri treatment type }+\epsilon
\end{aligned}
$$

All factors included in the model were found to be significant. Once again abundance was signifi cantly lower on sites with a low or medium salinity level (Fig. 6a), and mean fish weight was signifi cantly positively correlated with adult female lice levels. The sites that applied pyrethroids in the pretreatment period were found to have signifi cantly higher abundances of adult female lice than those that had no pretreatment episodes or that had administered emamectin benzoate (Fig. 6b). For peri treatment episodes, sites that administered pyrethroids had significantly higher adult female lice abundances than those that deloused with emamectin benzoate (Fig. 6c). No other significant differences were found between peri treatment types. Year was not included in the final model as it was not found to be a significant factor once pre and peri treatment types had been accounted for.

\section{Discussion}

The current study presents high quality sea lice counts from a large salmon producing area where strategic treatments against lice are being organized on a voluntary basis. The strategy was to keep lice levels as low as possible in early winter and spring, to minimize infection pressure on both farmed salmon and wild running salmonid fish in week 20 (Olsen 2005). Here the effect of this strategy is discussed. A formal test of the efficacy of strategic treatments as opposed to uncoordinated treatment regimes was not the purpose of this study. Results indicate that the mean abundance of adult female lice was below 0.25 in weeks 1620 of 2005 and 2006 on most sampled sites, but there were large variations between the fjord zones. The two innermost zones, B and C, had the lowest lice mean abundances, whereas the outermost zones, $\mathrm{D}$ 


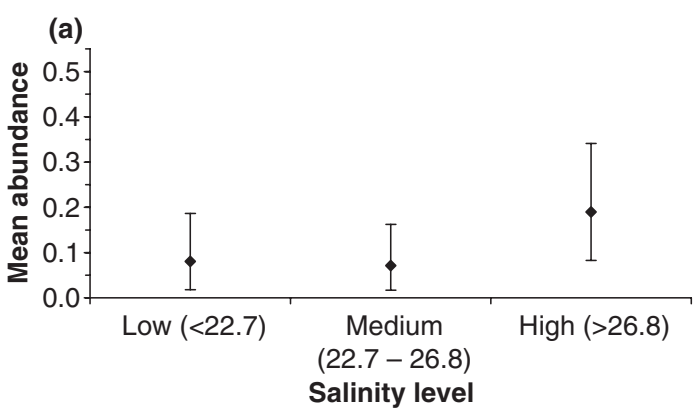

(b)

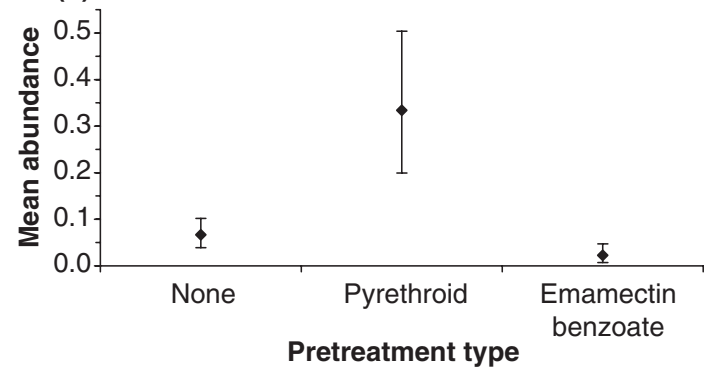

(c)

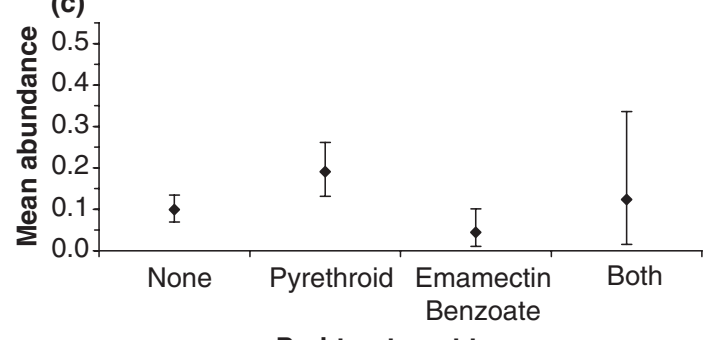

Peri-treatment type

Figure 6 Profile plot of least squares mean (GLM 3) adult female Lepeophtheirus salmonis abundance $( \pm \mathrm{SE})$ by (a) salinity level; (b) type of pretreatment, i.e. sea lice treatments given between week 48 of the previous year and week 15 of the current year; (c) type of peri-treatment, i.e. sea lice treatments given between the start of the counting period (week 16) and the date of the lice count.

and E, consistently had more lice. GLM analyses showed that the differences in adult female abun dance between the zones were associated with salinity differences, but also that emamectin ben zoate treatments administered strategically were associated with significantly reduced adult female lice abundance in the sample period. Furthermore, mean fish weight appeared to influence lice abun dance a factor not previously identified as significant in Norwegian studies of salmon lice abundance.

The models developed consistently showed a significant and positive relationship between adult female lice abundance and salinity. The large salinity differences are created by the geography of the fjord. It penetrates inland to the Hardanger mountain plateau, which has a general altitude of $1100 \mathrm{~m}$ above sea level and is snow covered in winter. In addition to rain, the inner fjord receives fresh water in the spring from melting snow and ice from glaciers, and this water flows out towards the coast on top of the more saline fjord water. The top layer becomes thinner and more brackish as it travels through the fjord, as fjord water is incorpo rated because of turbulence. The outer part of the fjord is also subjected to inflow of salt coastal water, which will further increase the salt content of the top water layer.

The salmon louse is a marine parasite, but adults can survive for a few weeks in fresh water (Hah nenkamp \& Fyhn 1985; McLean, Smith \& Wilson 1990; Finstad, Bjørn \& Nilsen 1995). It has been proposed that the preadult and adult stages can use substances from the fish host to remain hyperos motic (Hahnenkamp \& Fyhn 1985). Louse eggs fail to develop in $10 \%$ s, and nauplii do not develop into the infective copepodid stage at salinities below $25 \%$ (Johnson \& Albright 1991a). The pro nounced water layering in the fjord does, however, permit free swimming louse stages to select an acceptable salinity by vertical swimming (Heuch 1995). As fresh water lies on top of saltier water, the lice will reach higher salinity environments by swimming downwards. Copepodids actively avoid $20 \% \mathrm{~S}$ water, thus fish in such water will be protected against lice infection (Heuch 1995). In the present study salinity was recorded at $3 \mathrm{~m}$ depth, and it is likely that a substantial part of the farmed fish have spent enough time sufficiently high in the water column that the lice on them were affected by low salinity. The infection pressure on these fish would also have been reduced in periods of low salinity. In zones B and C, water of $20 \%$ S was recorded in 7 weeks or more of the spring and summer in 2005, and this has most likely helped produce the low abundances of both chalimus and adult female lice seen here.

The effect of low salinity was also apparent in the time between the strategic treatment and the first ordinary treatment against lice. In zones $\mathrm{B}$ and $\mathrm{C} \mathrm{a}$ mean of 30 weeks passed before new treatments were carried out, whereas the first farms in zones $\mathrm{D}$ and $\mathrm{E}$ were treated after only 15 weeks.

In the GLM analyses, salinity conditions in zones were binned in three groups, low $(<22.7 \% \mathrm{~S})$, medium (22.7 26.8\% S) and high ( $>26.8 \%$ S $)$. 
In both models 2 and 3, the two lower salinity levels had significantly fewer lice per fish than the high level. In view of the laboratory results cited above, it may have been expected that the low salinity group would exhibit significantly fewer lice per fish than the medium group. However, a recent aquarium based study found that copepodid survival is compromised at salinity levels below 27\% (Bric knell, Dalesman, O'Shea, Pert \& Mordue Luntz 2006).

The GLM analyses consider the effects of two different periods of delousing. The pretreatment periods cover the strategic delousing but also other treatments carried out long before the sample points, whereas the peri treatment periods cover the ordinary pest management which was under taken by each site independently. The treatments against lice in the fjord were not generally coordinated, except for the voluntary strategic campaigns.

The models indicate that emamectin benzoate treatments administered in either period were associated with significantly reduced adult female lice abundance. Fish treated with pyrethroids, in either period, carried significantly more lice at the time of sampling. Fish which were not treated at all had lower lice abundance than the pyrethroid treated fish. This apparent anomaly may be explained by the fact that HFN members were only asked to delouse if fish had a total mean abundance above 0.3 adult female lice in the strategic treatment period. The low lice abundance recorded on such fish during the subsequent sampling period confirms that farmers were correct in their judgement that delousing treatments were not required. Furthermore, it appears that these fish were not subject to significant additional infection before the sampling period.

Fish treated with emamectin benzoate appeared to have the lowest mean adult female lice abun dance. This may be because of the long lasting effect of this in feed medicine (Stone, Sutherland, Sommerville, Richards \& Endris 2000). In an HFN report on the strategic treatments, Olsen (2005) noted that the duration of the protection against lice using emamectin benzoate is particularly long in winter because of low water temperatures. Pyrethroid treatments are applied topically, and therefore do not give protection beyond the time of application. It is possible that infective stages of lice from other sites in the fjord infected fish which had been deloused early, or had been deloused by bath treatment. These lice must have grown into adults during winter. The generation time of the salmon louse has been estimated to $c a 8$ weeks at $10{ }^{\circ} \mathrm{C}$ (Johnson \& Albright 1991a), and as the tempera ture was below $10{ }^{\circ} \mathrm{C}$ during the winters, it is conceivable that early infections may have produced the populations of adult female lice found in the sampling period.

The results of the present study indicate that lice abundance is higher on larger fish a finding consistent with that reported on salmon farms in Scotland (Lees et al. 2008) and with experimental studies (Jaworski \& Holm 1992; Tucker, Sommer ville $\&$ Wootten 2002). The mechanism producing this phenomenon has not, however, been identified. It has been argued that larger fish have a higher number of lice simply because they have a larger area of skin on which the lice can settle (Jaworski \& Holm 1992). This would imply that some form of density dependent process exists on the fish, which regulates the number of parasites per unit area of skin. Another explanation is that lice from succes sive infections may accumulate on the fish. Mature female lice may live as long as 191 days at $7^{\circ} \mathrm{C}$ (Heuch, Nordhagen \& Schram 2000), which is longer than the time from attachment to the moult to adult (Johnson \& Albright 1991a). However, in an Irish study of farmed salmon, which were not treated against lice, mature lice disappeared from the fish before the maturation of the next genera tion was complete (Tully 1989). Under the present circumstances, where farmers are obliged to treat against lice if the abundance of adult females exceeds 0.5, accumulation of adult lice seems unlikely. The sampled sites very rarely exceeded this limit in the period of study.

In Hardanger as in Scotland, larger fish are generally deloused with pyrethroids, while fish in their first year at sea are treated with emamectin benzoate. It is possible that differences in treatment regimes, at different stages in the production cycle, leads to higher infection pressure in older fish. However, in an earlier Scottish study (Revie et al. 2002b), before emamectin benzoate was available for use, fish in their second year of production also consistently exhibited higher levels of lice infection. Furthermore, as mean fish weight and pre/peri treatment type were found to be significant factors in the models developed it would appear that differences in treatment regimes alone do not adequately explain the relationship between larger fish and higher levels of lice. 
This study represents an initial exploration of factors associated with lice infections on salmon farms in the Hardanger fjord between 2004 and 2006. Salinity, mean fish weight and treatment type were all shown to be significantly associated with lice abundance. While these findings represent a first step toward a better understanding of lice infections in a large Norwegian fjord, a full investigation of a wider set of risk factors will be made possible by the continuing data collection and analyses.

\section{Acknowledgements}

Thanks to the lice counting teams for an outstand ing effort; and to the members of the HFN for receiving the teams and sharing the data. We also acknowledge the help of FOM AS, the local veterinary service, which hosts the HFN office. This project was funded by the Fisheries and Aquaculture Industry Research Fund (Fiskeri og Havbruksnæringens Forskningsfond) and the Nor wegian Research Council.

\section{References}

Bjørn P.A., Finstad B., Nilsen R., Skaala Ø. \& Øverland T. (2007) Registreringer av lakselus på laks, sjøørret og sjørøye $i 2006$. Norsk Institutt for Naturforskning,No. 250, Trondheim.

Bricknell I.R., Dalesman S.J., O'Shea B., Pert C.C. \& Mordue Luntz A.J. (2006) Effect of environmental salinity on sea lice Lepeophtheirus salmonis settlement success. Diseases of Aquatic Organisms 71, 201-212.

Bush A.O., Lafferty K.D., Lotz J.M. \& Shostak A.W. (1997) Parasitology meets ecology on its own terms: Margolis et al. revisited. Journal of Parasitology 83, 575-583.

Finstad B., Bjørn P.A. \& Nilsen S.T. (1995) Survival of salmon lice, Lepeophtheirus salmonis Krøyer, on Arctic charr Salvelinus alpinus in fresh water. Aquaculture Research 26, 791-795.

Hahnenkamp L. \& Fyhn H.J. (1985) The osmotic response of the salmon louse, Lepeophtheirus salmonis (Copepoda: Caligidae), during the transition from sea water to fresh water. Journal of Comparative Physiology B 155, 357-365.

Heuch P.A. (1995) Experimental evidence for aggregation of salmon louse copepodids, Lepeophtheirus salmonis, in step salinity gradients. Journal of the Marine Biological Assosiation of the United Kingdom 75, 927-939.

Heuch P.A. \& Mo T.A. (2001) A model of salmon louse production in Norway: effects of increasing salmon production and public management measures. Diseases of Aquatic Organisms 45, 145-152.

Heuch P.A., Nordhagen J.R. \& Schram T.A. (2000) Egg production in the salmon louse [Lepeophtheirus salmonis (Krøyer)] in relation to origin and water temperature. Aquaculture Research 31, 805-814.
Heuch P.A., Bjørn P.A., Finstad B., Holst J.C., Asplin L. \& Nilsen F. (2005) A review of the Norwegian 'National action plan against salmon lice on salmonids': the effect on wild salmonids. Aquaculture 246, 79-92.

Jaworski A. \& Holm J.C. (1992) Distribution and structure of the population of sea lice, Lepeophtheirus salmonis Krøyer, on Atlantic salmon, Salmo salar L., under typical rearing conditions. Aquaculture and Fisheries Management 23, 577-589.

Johnson S.C. \& Albright L.J. (1991a) Development, growth, and survival of Lepeophtheirus salmonis (Copepoda: Caligidae) under laboratory conditions. Journal of the Marine Biological Association of the United Kingdom 71, 425-436.

Johnson S.C. \& Albright L.J. (1991b) The development stages of Lepeophtheirus salmonis (Krøyer, 1837) (Copepoda: Caligidae). Canadian Journal of Zoology 69, 929-950.

Johnson S.C., Treasurer J.W., Bravo S., Nagasawa K. \& Kabata Z. (2004) A review of the impact of parasitic copepods on marine aquaculture. Zoological Studies 43, 229-243.

Kålås S. \& Urdal K. (2007) Overvaking av lakselusinfeksjonar på tilbakevandra sjoaure i Rogaland, Hordaland og Sogn \& Fjordane sommaren 2006. Rådgivende Biologer AS, Bergen, Norway. Report no. 975, pp. 39.

Lees F., Gettinby G. \& Revie C.W. (2008) Changes in epidemiological patterns of sea lice infestation on farmed Atlantic salmon, Salmo salar L., in Scotland between 1996 and 2006. Journal of Fish Diseases 31, 259-268.

McLean P.H., Smith G.W. \& Wilson M.J. (1990) Residence time of the sea louse, Lepeophtheirus salmonis K., on Atlantic salmon, Salmo salar L., after immersion in fresh water. Journal of Fish Biology 37, 311-314.

Norwegian Fisheries Directorate 2008. http://www.fiskeridir.no/ fiskeridir/kystsone og havbruk/statistikk/statistikk for akvakultur/laks regnbue oerret og oerret

Olsen R.S. (2005) Prosjekt vinteravlusning i Hardangerfjorden 2004/2005. Report, Hardanger Fiskehelsenettverk, Eikelandsosen, pp. 14.

Olsen R.S. (2007) Prosjekt vinteravlusning i Hardangerfjorden 2005/06. Report, Hardanger Fiskehelsenettverk, Eikelandsosen, pp. 4.

Otterå H., Skilbrei O., Skaala Ø., Boxaspen K., Aure J., Taranger G.L., Ervik A. \& Borgstrøm R. (2004) Hardangerfjorden - produksjon av laksefisk og effekter på de ville bestandene av laksefisk. Fisken og havet 3, 1-42.

Revie C.W., Gettinby G., Treasurer J., Rae G. \& Clark N. (2002a) Temporal, environmental and management factors influencing the epidemiological patterns of sea lice (Lepeophtheirus salmonis) infestations on farmed Atlantic salmon (Salmo salar) in Scotland. Pest Management Science 58, 576584.

Revie C.W., Gettinby G., Treasurer J.W., Grant A.N. \& Reid S.W.J. (2002b) Sea lice infestations on farmed Atlantic salmon in Scotland and the use of ectoparasitic treatments. Veterinary Record 151, 753-757.

Stone J., Sutherland I.H., Sommerville C., Richards R.H. \& Endris R.G. (2000) The duration of efficacy following oral treatment with emamectin benzoate against infestations of sea lice, Lepeophtheirus salmonis (Krøyer), in Atlantic salmon Salmo salar L. Journal of Fish Diseases 23, 185-192. 
Tucker C.S., Sommerville C. \& Wootten R. (2002) Does size really matter? Effects of fish surface area on the settlement and initial survival of Lepeophtheirus salmonis, an ectoparasite of Atlantic salmon, Salmo salar. Diseases of Aquatic Organisms 49, $145-152$.

Tully O. (1989) The succession of generations and growth of the caligid copepods Caligus elongatus and Lepeophtheirus salmonis parasitising farmed Atlantic salmon smolts (Salmo salar L.). Journal of the Marine Biological Association of the United Kingdom 69, 279-287. 